\title{
Staff Conduct, Communication, Access to Service \& Customer Satisfaction: The Mediating Effect of Credibility
}

\author{
Junaid Zafar ${ }^{1, *}$, Nik Kamariah Nik Mat ${ }^{2}$, Theeb M.A. AlMotairi ${ }^{2}$, Meddour Houcine ${ }^{2}$, Egab AlOtaibi ${ }^{2}$, \\ Muhammad Saad AlAlawni², Jamal Mohammad Alekam ${ }^{2}$
}

${ }^{1}$ Department of Business Administration, University of Sargodha, Sargodha, 40100, Pakistan

${ }^{2}$ Othman Yeop Abdullah Graduate School of Business, Universiti Utara Malaysia, Sintok, 06010, Malaysia

\begin{abstract}
This study examines the direct effects of staff conduct, communication, access to service, and credibility on satisfaction towards telecommunication services in Malaysia. The study took place in a public university to see whether the lecturers are happy with the services provided by the telecommunication firms. There are a total of 100 responses to the questionnaire developed. The data is analyzed using Structural Equation Modeling (SEM) through AMOS. The goodness of fit indices of the revised structural model indicate adequate fit (GFI: 0.915, RMSEA: 0.048, Ratio: 1.21, P-value: 0.158). The regression parameter estimates show four significant relationships between credibility and staff conduct $(\beta=0.295$, $P$-value $=0.003$ and C.R=2.93), credibility and communication $(\beta=0.76$, $P$-value $=0.000$ and $C . R=8.996)$, satisfaction and access to service $(\beta=0.316$, $\mathrm{P}$-value $=0.000$ and $\mathrm{C} . \mathrm{R}=3.673)$ and satisfaction and credibility $(\beta=0.945$, $\mathrm{P}$-value $=0.035$ and $\mathrm{C} . \mathrm{R}=2.05$ ). The result is discussed in the context of improving telecommunication services in Malaysia.
\end{abstract}

Keywords Customer Satisfaction, Credibility, Access To Service, Staff Conduct, Communication

\section{Introduction}

In a globally competitive world, marketers are aiming for customer satisfaction in order to woo new clients. Customer satisfaction has always remained an important variable to study among marketers. Through customer satisfaction, customer loyalty can be enhanced by offering products and services that are in line with the needs and demands of the clients[1]. There has been an increasing emphasis on customers to know them[2].

One of ways firms can know their clients and adhere to the levels of satisfaction is through a channel of communication that informs of the loopholes[3]. A bond between service concern and consumers is present when a well knit channel is present to rally communication. The usage of telephones is a well-known direct marketing channel to enhance communication.

Malaysian telecommunication is booming in line with the vision 2020. The vision calls for making the country a $d$ e veloped one, another six years from now. The best companies include Digi, Telecom Malaysia, Celcom and Maxis that dominate the market. The services provided include

* Corresponding author:

jonaidzafar@googlemail.com(Junaid Zafar)

Published online at http://journal.sapub.org/economics

Copyright $(C) 2012$ Scientific \& Academic Publishing. All Rights Reserved traditional telecommunications, Internet Protocol services, wireless services, and broadband. Besides a number of value added services are provided like Short Message Service (SMS), Wireless Application Protocol (WAP), Subscription Services (SS), General Packet Radio Services, and Third Generation services. The issue of understanding customers' satisfaction among telecommunication providers in a progressive country such as Malaysia is hence, imperative.

Consumer satisfaction should include an element of staff conduct. It is necessary for firms to train the employees at the level that is enough to take part in service provision. The staff should be responsive as well as competitive to the needs of the consumer[4].

Here, the researchers had also included access to service which forms the relationship between customer satisfaction as direct and credibility as mediating. The term here is known as planning, making aware as well asnon-discriminating ways to access the host of services[5]. There is a need to access the variety of information or assistance when there is lack of services from the firm i.e., when there is a gap between the needs of consumer and what is supplied. The terms accessibility has been defined by Owusu-Frimpong, Nwankwo \& Dason[6] as: "ease with which service providers can be reached and service consummated (e.g. location, opening hours, logistical issues such as car parking and facilities for people with disabil- 
ity)"

Through good clear communication, the firm forms brand credibility[7]. The term can be taken as an investment by the firms to pursue a differentiation programme by offering a new range of goods. Li, Wang \& Yang[8] describe credibility as source and corporate. When credibility is source it is taken by the information receiver as credible knowledge; thus influences the attitudes to purchase or not. The other term corporate credibility is taken as the belief in the firms' trustworthiness, as well as expertise and likeableness by the people who are interested in it i.e., stakeholders.

Thus, this study intends to examine the effects of staff conduct, communication, access to service and credibility on customer satisfaction towards services provided by telecommunication providers in Malaysia.

\section{Literature Review}

Past empirical studies had identified diversified numbers of customer satisfaction predictors. Yang \& Peterson[1] postulate that firms have a penchant towards consumer trustworthiness and thus lay a premium on satisfaction and perceived value. The determinants of online customer satisfaction are customer services, order fulfillment, ease of use, product portfolio, and security or privacy. Adversely, Babacus, Bienstock \& Van Stock[9] found that customer satisfaction has a more direct effect on store level performance; whereas a mediating effect is found between Performance Expectation (P.E) or perceived quality and performance. The results suggest that service and merchandize quality have an affect on performance, sales and consumer growth. Stank, Daugherty and Ellinger[2] found that vendors, some of them, are not able to get consumer feedback. This feedback is important for new ideas, and buyer seller interaction. It is therefore suggested that customer satisfaction should be gauged by proper feedback.

Tyler and Blader[10] found that social values have a hand in shaping behaviour. To bring employees behaviour into corporate code of conduct the employers should tap into employees' behaviour. Also mentoring, sanctions or rewards are also there to help employers to let the staff be rule driven. In a study by Erwin[11], it was found that codes of conduct have the ability to transform culture of the firm. Companies with a code of conduct were outperforming those that do not have it. In another study, Avkiran[4] found various "cost-effective" technologies undermining the essence of successful customer service in the form of human touch

Carrie 're and Bourque[12] found internal communication practices depend on the information that is appreciated by employees. The managers within should be clear as to the 2 Q's of information i.e., quality and quantity if they design the internal communication ways. In a study by Agnihotri, Rapp and Trainor[13] found managers to benefit by extending sales force training to inculcate technical knowledge, communication skills. Here technology can aid in customer satisfaction through improved information communication.
In a study by Webster and Sunderam[3] found two communication styles, (1) affiliativeness and (2) dominance, having to show link with evaluations of the service. Affiliative styles produced greater satisfaction, whereas dominant type resulted in less favorable evaluations.

Brennan and Gallagher[5], suggests Government in Britain put importance on access for consumers to information and advice services on different issues like online shopping and price increase. It is found that approximately two thirds of the buyers were worried about ignorance of rights to complain and preparing for greater consumer education. Owusu-Frimpong et al[6] found varying access experiences among people taking public and private medical facilities. Public, as opposed to private, healthcare users had a rough experience in relation to getting attention from doctors, time taken to get appointments, access to core treatment and opening hours. It is therefore required that access-to-care problems need to be addressed by managers and healthcare providers so that quality of service delivery and patient satisfaction is addressed. Alternatively, Cullen[14] found little or no training access to improve skills among the unemployed. These skills include soft and aesthetic which result in a contradiction between the employed and unemployed.

Ghorban and Tahernejad[7] found brand credibility to have a positive impact on word of mouth through customers' satisfaction and loyalty. One way to lure new customers to buy the products and services is through creating brand credibility for companies. In another study by Li et al[8] found that firms can increase the strength, favorability, and uniqueness of their brands through outstanding logo displays on product packaging. There is a need to understand what a particular brand means to customers. Like in China people attach great importance to car procurement. It should be known that switching costs serve as a moderator only when a firm achieves above-average performance. Credibility has been used as a mediating variable between CS and loyalty by[15],[16]. But the mediating relationship with communication, access, conduct and CS has never been studied.

\section{Theoretical Underpinning of Study}

The underlying model of this study is the Oliver's[18] model of expectation and disconfirmation approach to satisfaction. Oliver[18] suggests that the degree of satisfaction as present in a person has four levels to it. According to Day[19] satisfaction is the evaluation within the conscious or it is a judgment that product or store is suitable. The process entails consumer intention to purchase, having the feeling that the retailer will achieve certain performance level. The consumer then shops at the store on the pre-established presumptions about the level of performance exhibited by that store. This is the second step. There is a comparison of perceptions as held by the consumer whether it exceeds expectations about the store or decreases. Then the perceived disconfirmation has the determination value as held by the store. This is the third level. 
Then the consumer will patronize the store based on the satisfaction level. This is the last level. Here the intentions can be described as the future behavior that is to be exhibited by the consumer. So the model is given as:

Previous research has been done extensively by taking Oliver[18] model of Disconfirmation-Expectation-Satisfaction. According to Lee et al.[20] expectations are not an important forecaster of satisfaction for innovative shopping experience yet satisfaction is primarily driven by the performance of the sites and predicted by disconfirmation of expectations. According to Chen and Chen[21] make known the direct effects of the quality of experience on perceived value and satisfaction. However, it is the indirect and not direct effects of the quality of experience that hinge on behavioral intentions. The relationship is mediated by perceived value and satisfaction. $\mathrm{Chi}$ and $\mathrm{Qu}[22]$ maintain that destination image directly influences attribute satisfaction; destination image and attribute satisfaction are direct antecedents of overall satisfaction; and overall satisfaction and attribute satisfaction has direct and positive impact on destination loyalty. Lai et al.[23] have it that value has both a direct and indirect impact on customer loyalty. Damhorst et al.[20] reveal that motivation is a determinant of the visit assessment criteria. However, this investigation also found the existence of certain elements, which are independent of the reasons that motivate but which affect general satisfaction.

\section{Methodology}

The sample is taken from 100 academicians in one of Malaysia's Universities. The study identifies four antecedents of customer satisfaction i.e., (i) staff conduct, (ii) communication, (iii) access to service and (iv) credibility. Each of the antecedents is measured using a 7-point Likert scale. The primary data is collected through questionnaire. There are a total of 47 males and 53 females in the study. 155 questionnaires were sent out of which 100 were put to task. The data is analysed using Structural Equation Modelling and AMOS 16. Likewise, the factors that make the clients loyal include credibility of service. Simple Random Sampling was done to gather data. The 100 dataset were coded and saved into SPSS version 14 and analysed using AMOS version 16.0. The revised structural model achieves model fit as shown in Figure 1.

The goodness of fit indices of the revised model indicate adequate fit compared to the cut-off points (GFI: 0.915: >0.90; RMSEA: 0.048: $<0.08$; Ratio cmindf: $1.21:<2$, p-value: $0.158 ;>0.05$ ). Thus, the hypothesized findings could be generalized to the population.

From the 7 direct relationships hypothesized, four relationships are supported: The regression parameter estimates show four significant relationships between: staff conduct and credibility ( $\beta=0.295$, P-value $=0.003, C . R=2.93$ ), communication and credibility $(\beta=0.76, p<0.001, C . R=8.996)$, access and satisfaction $(\beta=0.316, p<0.001, C . R=3.673)$ and credibility and satisfaction $(\beta=0.945, p<0.05, C . R=2.05)$. Conversely, the relationship between access and satisfaction $(\beta=-0.051$, $P$-value $=-0.569$ and $C . R=-0.570)$, staff conduct and satisfaction and $(\beta=0.065, \quad P$-value $=0.676$ and C. $R=0.156)$ and communication and satisfaction $(\beta=-0.289$, $\mathrm{P}$-value $=0.415$ and $\mathrm{C} . \mathrm{R}=-0.815$ ) are found to be insignificant. Finally, credibility is found to have non-mediating effects between exogenous and endogenous variables.

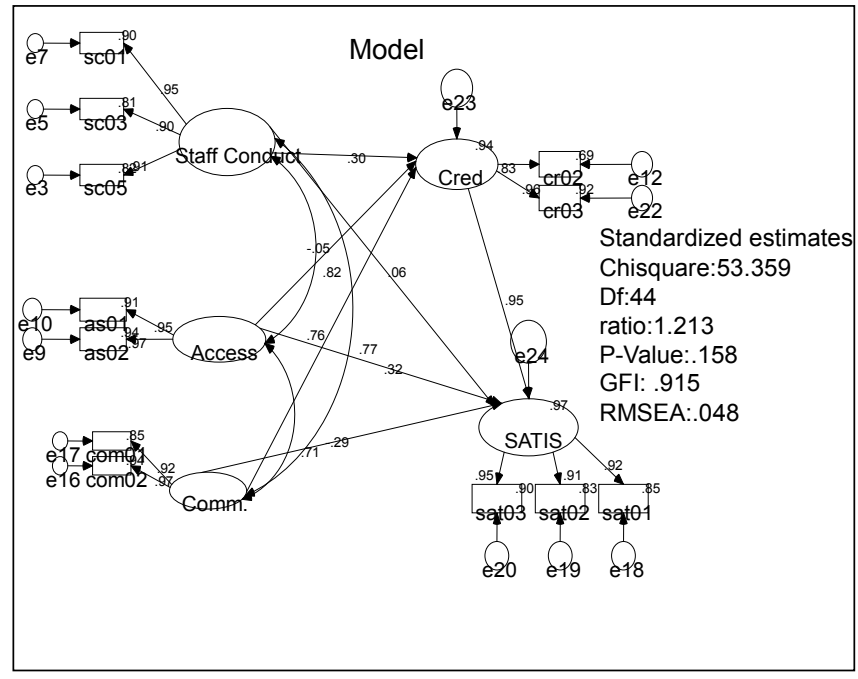

Figure 1. Standardized Estimates

\section{Conclusions}

The study tries to find out as to what level the academicians feel satisfied with the services of telecommunication giant providers. The findings are depictive of the fact that the company should strive towards improving the services to ensure satisfied customers. They should work upon the ones in place and put some new practices into pipeline. The consumer can develop credibility for the product if the company has all the services in line with needs and wants of the users. For this the telecom giant should have knowledge of market and its competitors. According Avkiran[4] quality of service is a key to competitive edge over its rivals. The staff should be flexible in its approach. A culture of smile and feedback should be introduced so that every person has access to services. It could be inferred that the aim of business is to work on clients' access and reduce time for service. Since academicians take priority in accessing World Wide Web, the 'business' should provide state art of the art services round the clock.

Some of the limitations of the study are that data is gathered in one university. In future, data could be gathered from multiple sources. Different strata can be put in like students, blue and white collar workers to see the effects of the said variables on the satisfaction. The sample size is relatively small. A more cosmopolitan city like Kuala Lumpur or Johor can be used. Cross country comparison can be conducted so as to see how Malaysia is faring in the region i.e. Far East. The research methodology employed in the study is quanti- 
tative. In future qualitative research can be carried out to know the whys and how's. Moreover interviews can be conducted to account for details.

\section{ACKNOWLEDGEMENTS}

We would like to thank Prof Dr. Nik Kamariah Nik Mat and Sukma Pea for their helpful comments and assistance on an earlier version of this paper.

\section{REFERENCES}

[1] Yang, Z., and Peterson, R. T. Customer Perceived Value, Satisfaction, and Loyalty: The Role of Switching Costs. Psychology \& Marketing, 21(10), 799-822 (2004).

[2] Stank, T. P., Daugherty, P. J., and Ellinger, A. E. Voice of the Customer: The Impact on Customer Satisfaction. International Journal of Purchasing and Materials Management, 33(4), 2-9 (1997).

[3] Webster, C., and Sundaram, D. S. Effect of service provider's communication style on customer satisfaction in professional services setting: the moderating role of criticality and service nature. Journal of Services Marketing, 23(12), 104-114 (2007).

[4] Avkiran, N. K. Quality customer service demands human contact. International Journal of Bank Marketing, 17(2), 61-71 (1999).

[5] C. Brennan, and K. Gallagher,. Consumer Support Networks: improving consumer advice in the UK. International Journal of Consumer Studies, 26, 3, September 2002, pp227-238, 2002.

[6] Owusu-Frimpong, N., Nwankwo, S., and Dason, B. Measuring service quality and patient satisfaction with access to public and private healthcare delivery. International Journal of Public Sector Management, 23(3), 203-220 (2010).

[7] Ghorban, Z. S., and Tahernejad, H. A Study on Effect of Brand Credibility on Word of Mouth: With Reference to Internet Service Providers in Malaysia. International Journal of Marketing Studies, 4(1), 26-37 (2012).

[8] Li, Y., Wang, X., and Yang, Z. The Effects of Corporate-Brand Credibility, Perceived Corporate-Brand Origin, and Self-Image Congruence on Purchase Intention: Evidence from China's Auto Industry. Journal of Global Marketing, 24, 58-68 (2011)

[9] BabaKus, E., Bienstock, C. C., and Van Scotter, J. R. Linking Perceived Quality and Customer Satisfaction to Store Traffic and Revenue Growth. Decision Sciences, 34(4), 713-737 (2004).

[10] Tyler, T. R., and Blader, S. L. Can Businesses Effectively Regulate Employee Conduct? The antecedents of rule following in work settings. Academy of Management Journal, 48(6), 1143-1158 (2005).
[11] Erwin, P. M. Corporate Codes of Conduct: The Effects of Code Content and Quality on Ethical Performance. Journal of Business Ethics, 99, 535-548 (2011).

[12] Carrie're, J., and Bourque, C. The effects of organizational communication on job satisfaction and organizational commitment in a land ambulance service and the mediating role of communication satisfaction. Career Development International, 14(1), 29-49 (2009).

[13] Agnihotri, R., Rapp, A., and Trainor, K. Understanding the role of information communication in the buyer-seller exchange process: antecedents and outcomes. Journal of Business \& Industrial Marketing, 24(7), 474-486 (2009).

[14] Cullen, A. M. Unemployed job seekers' access to interactive service work. Employee Relations, 33(1), 64-80 (2011).

[15] Garbarino, E., Johnson, M.S. (1999). The different roles of satisfaction, trust, and commitment in customer relationships, Journal of Marketing, Vol. 63 No.4, pp.70-87.

[16] Delgado-Ballester, E., Munuera-Alemn, J.L., Yagüe-Guillén, M.J. (2003), "Development and validation of a brand trust scale", International Journal of Market Research, Vol. 45 No.1, pp.35-52

[17] Oliver, R. A cognitive model of the antecedents and consequences of satisfaction decisions. Journal of Marketing Research, 17, 460-469 (1980).

[18] Day, R. L. Extending the concept of consumer satisfaction in advances in consumer research, Vol. IV, William D Perreault, Jr., Ed. Atlanta, GA: Association of Consumer Research (1977).

[19] Lee, H., Damhorst, M. L., Campbell, J. R., Loker, S., and Parsons, J. L. Consumer satisfaction with a mass customized Internet apparel shopping site. International Journal of Consumer Studies, 35(3), 316-329 (2011).

[20] Chen, C., and Chen, F. Experience quality, perceived value, satisfaction and behavioral intentions for heritage tourists. Tourism Management, 31(1), 29-35 (2010).

[21] Chi, C., and Qu, H. An examination of the effects of motivation and satisfaction on destination loyalty: a structural model. Tourism Management, 29(4), 624-636 (2008).

[22] Lai, F., Griffin, M., and Babbin, B. J. How quality, value, image, and satisfaction create loyalty at a Chinese telecom. Journal of Business Research, 62(10), 980-986 (2009).

[23] Devesa, M., Laguna, M., and Palacios, A. The role of motivation in visitor satisfaction: Empirical evidence in rural tourism. Tourism Management, 31(4), 547-552 (2010).

[24] Sallam, M. A. The Impact of Source Credibility on Saudi Consumer's Attitude toward Print Advertisement: The Moderating Role of Brand Familiarity. International Journal of Marketing Studies, 3(4), 63-77 (2011).

[25] Taylor, J. R., and Shouls, S. Transforming access: the role of data within service improvement to transform access to services. Clinical Governance: An International Journal, 13(1), 8-18 (2008) 